\title{
Smart in-situ thermo-responsive and ion activated ophthalmic sol-gel system of fluconazole
}

\author{
Mohammed MUQTADER AHMED ${ }^{1 *}\left(\mathbb{D}\right.$, Farhat FATIMA ${ }^{1}$ (D), Md Khalid ANWER ${ }^{1}$ \\ 1 Department of Pharmaceutics, College of Pharmacy Prince Sattam Bin Abdulaziz University AlKharj, Saudi Arabia. \\ * Corresponding Author. E-mail: muqtadernano@gmail.com (M.M.); Tel. +966-506 735642.
}

Received: 25 August 2020 / Revised: 28 January 2021 / Accepted: 23 February 2021

\begin{abstract}
The objective of the current investigation is the development and characterization of in-situ ophthalmic formulation of fluconazole for sustained release at the eye site for a prolong period of time. Sol-gel fluconazole in-situ formulation was prepared by thermo-responsive pluronic F127, $\mathrm{Na}^{+}$activated sodium alginate alone and in combination, characterization parameters include FTIR spectroscopy, Visual assessment and clarity test, Gelling ability test, $\mathrm{pH}$ testing, drug assay, In-vitro drug release and optimized formulation was evaluated for In-vitro antifungal studies by comparing with marketed formulation of fluconazole. Optimized formulation F8 composed of fluconazole $(0.3 \% \mathrm{w} / \mathrm{v})$, Pluronic F127( $1 \% \mathrm{w} / \mathrm{v})$, sodium alginate $(0.5 \% \mathrm{w} / \mathrm{v})$, sodium chloride $(0.9 \mathrm{w} / \mathrm{v})$, benzalkonium Chloride $(0.01 \% \mathrm{w} / \mathrm{v})$ and acetate buffer $\mathrm{pH} 4$ up to $100 \% \mathrm{w} / \mathrm{v})$, showed drug-polymer compatibility as per FTIR, high gelling consistency on contact with simulated physiological conditions, $6.9 \mathrm{pH}$, drug assay was estimated $(99.89 \pm 0.78 \%)$ with $100 \%$ in-vitro drug released for about 6 hours. The in-vitro antifungal study was found to be $18.87 \pm 0.65 \mathrm{~mm} ; 20.76 \pm 0.23$ $\mathrm{mm}$ in comparison to marketed fluconazole conventional gel formulation (15.98 $\pm 0.98 \mathrm{~mm} ; 18.98 \pm 0.76 \mathrm{~mm})$ for Candida albicans and Aspergillus niger pathogenic fungal strains respectively. Prepared in-situ ophthalmic sol-gel formulation of fluconazole could be considered as efficient delivery system to sustained the drug at the target site and effectively eradicating deeply rooted pathogenic fungal stains.
\end{abstract}

KEYWORDS: Thermos-responsive; $\mathrm{Na}^{+}$activated; sol-gel; fluconazole; Candida albicans.

\section{INTRODUCTION}

Special sense organ eye should be dealt with great attentiveness, while delivering the drug. Anatomical position and physiological function of eye hindered most of the conventional drug therapies leading to failure in attaining the desired drug concentration [1]. Continuous movement of eyeball (3-5/sec or over a million times/day) besides lacrimation flow rate of lubrication about $(170-260 \mathrm{ml} / \mathrm{min})$ and posture of body could influence the absorption of drugs [2]. Cornea the outermost protective layer composed of five layers serves as barrier against, dirt, microbes and protect the eye from hazardous effects of radiations to some extends [3]. Lipoidal cells $(90 \%)$ of cornea possess significant resistance for topically applied drugs [4]. Pharmacokinetics of ophthalmic dosage explains the conventional dosage of eye drop 5 equivalent of $0.25 \mathrm{ml}$ distributes in $7 \mu \mathrm{L}$ of tear fluid leading to $47 \mu \mathrm{L}$ volume of distribution ( $\mathrm{Vd}$ ) with elimination rate constant of $0.02 \mathrm{~min}-1$ [5]. Lacrimal drainage also reduces the active concentration of the drug at the required site. The aforementioned factors emphasis the failure of conventional eye drops to achieve therapeutic efficacy. Superficial eye fungal infection more predominant with frequent reoccurrence [6]. Infection at the eye site considered to be one of the main causes for keratitis, endophthalmitis, dacryocystitis and orbital cellulitis results in ocular morbidity followed by impaired or loss of vision [7]. Antifungal drugs widely used for treatment, their administration in eye drops couldn't be able to eradicate the fungal infection completely [8]. Fluconazole considered being the drug of first-line therapy for many ocular fungal infections caused by Candida and Tinea pathogenic species [9]. Formulation scientist has applied novel drug delivery and nano-technologies in order to conquer the barriers to achieve desired drug concentration and target drug to the site of action [10]. First controlled pilocarpine delivery Ocusert ${ }^{\circledR}$ was fabricated for management of glaucoma conditions, permeation enhancers $\beta$-cyclodextrin employed to increase the solubility and increase permeation, drug encapsulated noisome, liposome, polymeric nanoparticles and nanocrystals were also applied to temporal and targeted delivery of drug at the eye site [11,12]. In-situ ophthalmic delivery systems were considered to be patient compatible, retained at the eye site for prolong period of time thereby increasing the contact time, absorbtion and

How to cite this article: Muqtader MA, Fatima F, Anwer MK. Smart in-situ thermo-responsive and ion activated ophthalmic sol-gel system of fluconazole. J Res Pharm. 2021; 25(2): 173-178. 
bioavailability of the drug. The drug presented in solution physical state offered easy accessible and dose administration that on contact with the eye site due to the physiological temperature and alkaline environment the instilled solution turns to gel, henceforth called sol-gel systems.

\section{RESULTS AND DISCUSSION}

\subsection{FTIR spectroscopy}

FTIR spectrum of FLZ showed in fig-1 represents O-H stretching vibrations at $3350 \mathrm{~cm}^{-1}$, aromatic C-H stretching vibrations at $3000 \mathrm{~cm}^{-1}$, aromatic $\mathrm{C}=\mathrm{N}$ stretching vibrations at $1650 \mathrm{~cm}^{-1}$ and aromatic $\mathrm{C}-\mathrm{F}$ stretching vibrations at 1000- $1400 \mathrm{~cm}^{-1}$. Most of these fingerprints region peaks of fluconazole get shifted and shorten in the formulation composed drug and polymers, representing no chemical interaction of drug with the polymers and considered to be the compatible (Figure 1).

\subsection{Visual assessment and clarity test}

The evaluation parameters revealed; sol-gel systems prepared by pluronic F-127 (F1-F3) were transparent and cleared in contrast to sodium alginate sol-gel formulation light yellow in color with pale yellow and cloudiness in F6. Visual appearance and clarity test showed a light yellow color and cloudiness for formulation F6 and F9. Sol-gel F8 formulation showed transparency. Results are given in Table 1.

\subsection{Gelling ability test}

Gelling ability was found to increase with increase in the polymer concentration, formulation F3, F5, F6, F8 and F9 indicated immediate and extended gelation (Table 1).

\section{4. $\mathrm{pH}$ testing}

All the formulation had the biocompatible $\mathrm{pH}$ suitable for installation in the eye, without causing any irritation. Results are given in Table 1.

\subsection{Drug assay}

Drug content estimation was found to be within the prescribed limits of official compendia. Results are given in Table 1.

\subsection{In-vitro drug release}

In-vitro drug release was decreased with an increase in the polymer concentration, that could be attributed due to an increase in viscosity, which may hinder the drug molecule to permeate in the diffusion medium. Percentage FLZ released found to be $99.99 \%, 94.11 \%, 89.99 \%$ for F1-F3 respectively, Figure 2. Sol-gel the formulation prepared by sodium alginate (F4-F6) showed decrease released in comparison to the pluronic127 formulation (F1-F3), Figure 3. Formulations F7-F9 showed relatively sustained drug released due to synergistic thixotropic property of pluronic F-127 and sodium alginate, Figure 4. From in-vitro drug release study F8 formulation was considered to be an optimized showed 100\% drug released in 6 hours. Drug release study could be correlated with the results reported by Üstündağ Okur et al [13].

\subsection{In-vitro antifungal studies}

Formulation, F8 was considered for further testing its efficacy against the pathogenic fungal strains by in-vitro antifungal study, Figure 5. Antifungal study revealed zone of inhibition of FLZ as positive control $(12.87 \pm 0.89 \mathrm{~mm}, 18.65 \pm 0.87 \mathrm{~mm})$ for C. albicans and A. niger respectively. Comparison of marketed FLZ gel $(15.98 \pm 0.98 \mathrm{~mm} ; 18.98 \pm 0.76 \mathrm{~mm})$ and optimized F8 showed $(18.87 \pm 0.65 \mathrm{~mm} ; 20.76 \pm 0.23 \mathrm{~mm})$ for C. albicans and A. niger respectively.

\section{CONCLUSION}

Ophthalmic fungal infection, one of the persistent causes of ocular morbidity. The efficacy of treatment depends on the residence and localization of antifungal drugs in the corneal region. Optimized formulation F8 composed of both pluronic F-127 and sodium alginate converts the solution to gel by physiological temperature $\left(37^{\circ} \mathrm{C}\right)$ and $\mathrm{Na}^{+}$ions of lacrimal fluid. Formulation F8 sol-gel transition leads to an increase in viscosity, longer residence and sustained drug release with effectiveness against pathogenic strains (C. albicans and A. niger) make it suitable for the treatment of topical ophthalmic fungal infection. 

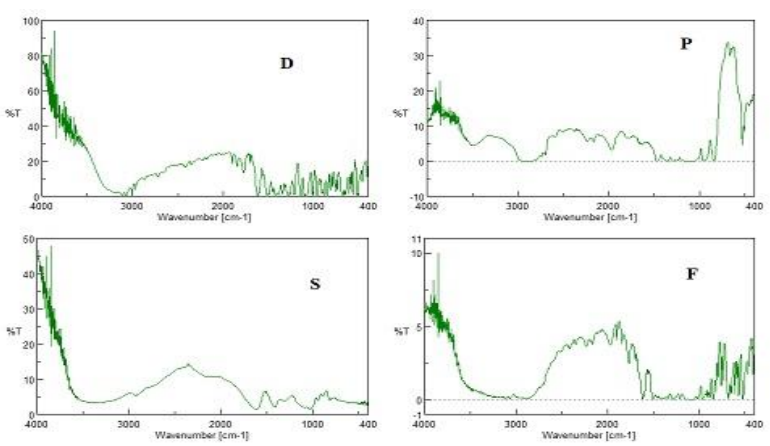

Figure 1. FTIR spectrums of (D) FLZ, (P) pluronic F127, (S) sodium alginate and (F) formulation.

Table 1. Evaluation parameters of fluconazole in-situ ophthalmic sol-gel.

\begin{tabular}{cccccc}
\hline \multirow{2}{*}{$\begin{array}{c}\text { Formulation } \\
\text { code }\end{array}$} & \multicolumn{5}{c}{ Evaluation Parameters } \\
\cline { 2 - 6 } & Visual appearance & Clarity & Gelling ability & $\mathbf{p H}$ & (\%) Drug content \\
\hline F1 & Transparent & Clear & + & 6.87 & $99.76 \pm 0.89$ \\
F2 & Transparent & Clear & ++ & 7 & $98.99 \pm 0.98$ \\
F3 & Transparent & Clear & +++ & 6.7 & $99.08 \pm 0.78$ \\
F4 & Light yellow & Clear & ++ & 6.9 & $99.09 \pm 0.67$ \\
F5 & Light yellow & Clear & +++ & 7.2 & $98.98 \pm 0.87$ \\
F6 & Pale yellow & Cloudy & +++ & 7.4 & $98.78 \pm 0.99$ \\
F7 & Light yellow & Cloudy & ++ & 6.8 & $98.99 \pm 0.76$ \\
F8 & Transparent & Clear & +++ & 6.9 & $99.89 \pm 0.78$ \\
F9 & Light yellow & Cloudy & +++ & 7.1 & $98.89 \pm 0.98$ \\
\hline
\end{tabular}

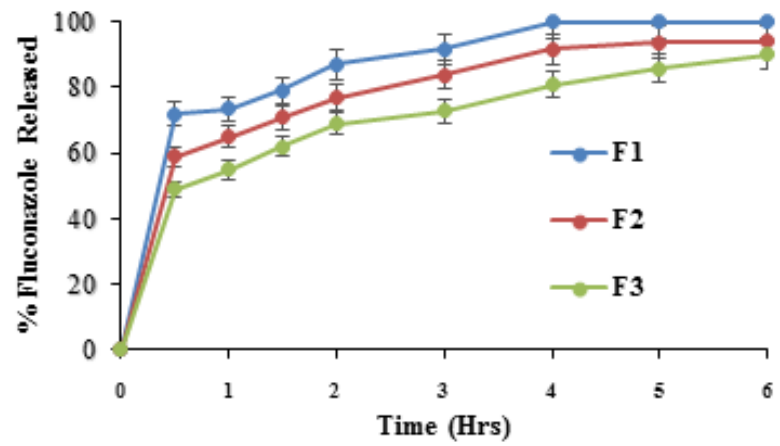

Figure 2. In-vitro drug release of Pluronic F-127 FLZ in-situ sol-gel.

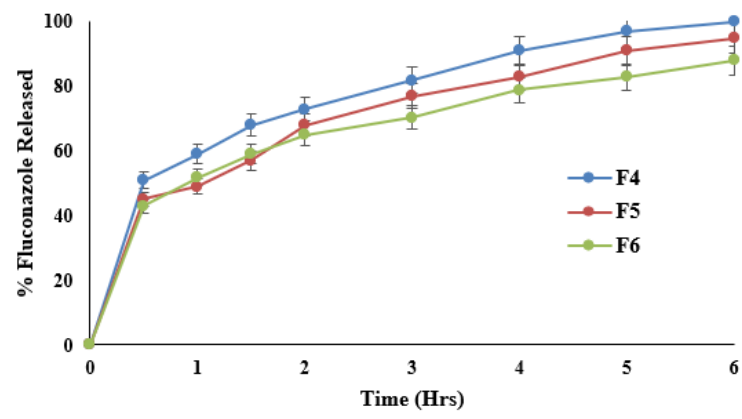

Figure 3. In-vitro drug release of sodium alginate FLZ in-situ sol-gel. 


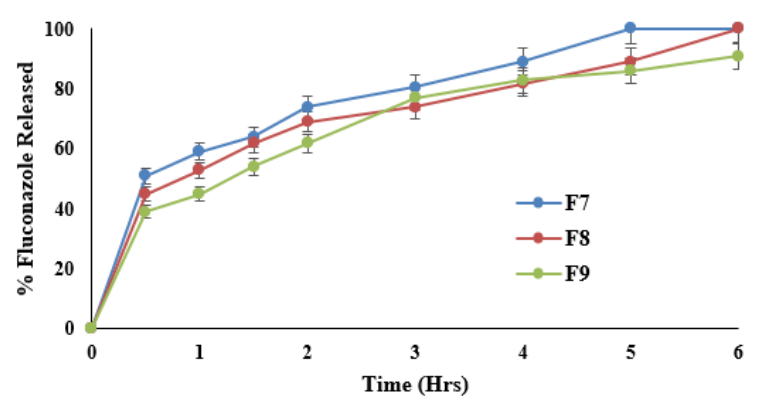

Figure 4. In-vitro drug release of Pluronic F-127 and sodium alginate FLZ in-situ sol-gel.

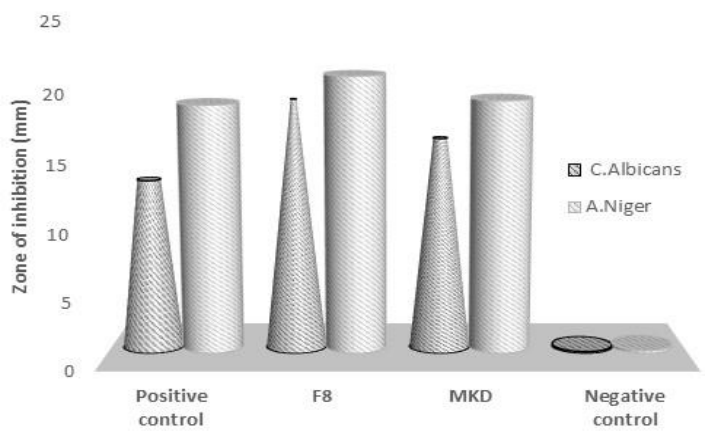

Figure 5. In-vitro Antifungal study of FLZ in-situ sol-gel.

\section{MATERIALS AND METHODS}

Materials: Fluconazole was obtained as drug gift sample from JPI, Riyadh. Sodium alginate and Pluronic F-127 purchased from Sigma Aldrich, United States. Sodium Chloride and Benzalkonium chlorides were procured from Loba Chemie Pvt Ltd, India. All the other chemicals used were of analytical grades and used as its supplied without any purification and testing. Ultrapure water used was processed by Milli- ${ }^{\circledR}$ Integral Water Purification System.

\subsection{Preparation of fluconazole in-situ ophthalmic sol-gel}

Drug - polymeric solutions were prepared by dissolving fluconazole (FLZ) $0.3 \% \mathrm{~W} / \mathrm{W}$ and required concentration of sodium alginate (hot-aqueous phase), pluronic F127 (cold aqueous phase) in alone and combinations as per Table 2, using ultrapure water. Sodium chloride and Benzalkonium chloride solutions added in the above drug-polymeric solution by continuous mixing on the magnetic stirrer at $400 \mathrm{rpm}$ with heating $\left(50^{\circ} \mathrm{C}\right.$ on ceramic plate (Thermo Fisher Scientific, Massachusetts USA). Final volume was made up to $100 \mathrm{~mL}$ and $\mathrm{pH}$ was adjusted with acetate buffer to $\mathrm{pH} 4$ [14]. Entire process of preparation was done under aseptic conditions of BSC class II cabinets (LabGard ES NU-437S Class II Biosafety Cabinet, USA).

Table 2. Preparation of fluconazole in-situ ophthalmic sol-gel.

\begin{tabular}{lccccccccc}
\hline \multirow{2}{*}{ Composition (\%W/V) } & \multicolumn{8}{c}{ Formulation Code } \\
\cline { 2 - 10 } & F1 & F2 & F3 & F4 & F5 & F6 & F7 & F8 & F9 \\
\hline Fluconazole & 0.3 & 0.3 & 0.3 & 0.3 & 0.3 & 0.3 & 0.3 & 0.3 & 0.3 \\
Pluronic F127 & 0.5 & 1 & 1.5 & - & - & - & 0.5 & 1 & 0.5 \\
Sodium Alginate & - & - & - & 0.5 & 1 & 1.5 & 0.5 & 0.5 & 1 \\
NaCl & 0.9 & 0.9 & 0.9 & 0.9 & 0.9 & 0.9 & 0.9 & 0.9 & 0.9 \\
Benzalkomium Chloride & 0.01 & 0.01 & 0.01 & 0.01 & 0.01 & 0.01 & 0.01 & 0.01 & 0.01 \\
Acetate Buffer pH 4 & 100 & 100 & 100 & 100 & 100 & 100 & 100 & 100 & 100 \\
\hline
\end{tabular}




\subsection{Characterization of $i n-s i t u$ ophthalmic sol-gel}

\subsubsection{FTIR spectroscopy}

FTIR analysis performed in the region of 4000 to $400 \mathrm{~cm}^{-1}$ by the Fourier transformer spectroscopy technique (Perkin-Elmer spectrophotometer, Germany; model 2000 FTIR). Drug (FLZ) and polymer compatibility study was done by taking FLZ, and polymers; pluronic F127, sodium alginate alone and in combination with potassium bromide spectra were interpreted for possible physicochemical interactions [15].

\subsubsection{Visual assessment and clarity test}

In order to examine the formulation and confirm the negative grittiness and particulate matter. Prepared ophthalmic solutions were examined against black and white background [16].

\subsubsection{Gelling ability test}

The prepared formulation was dropped into vial $(2 \mathrm{~mL})$ filled with simulated tear fluid maintained in physiological conditions. (Simulated tear fluid - STF composed of $\mathrm{NaCl} 0.67 \mathrm{~g}, \mathrm{NaHCO}_{3} 0.20 \mathrm{~g}, \mathrm{CaCl}_{2} \cdot 2 \mathrm{H}_{2} \mathrm{O}$ $0.008 \mathrm{~g}$, in deionized water to make $100 \mathrm{~g}$ ). The gelling ability was visually observed, sol-gel transitions then noted [17].

\subsection{4. $p H$ testing}

All the formulations were assessed for hydrogen potential using $\mathrm{pH}$ meter ( $3510 \mathrm{pH}$ Meter, Jenway, UK). Formulation first dissolved in ultrapure water and electrode is dipped into sample and $\mathrm{pH}$ was noted.

\subsubsection{Drug assay}

All the formulation was evaluated for drug content estimation by diluting $2 \mathrm{~mL}$ of sample up to $100 \mathrm{~mL}$ of simulated tear fluid $\mathrm{pH}$ 7.4. The concentration of drug followed by \% drug content was estimated by UVspectrophotometric analysis (Jasco v-630 spectrophotometer, German) at $\lambda_{\max } 261 \mathrm{~nm}$ [18].

\subsubsection{In-vitro drug release}

Drug diffusion study was performed in fabricated diffusion cell using cellophane membrane (Mol. Wt. $14 \mathrm{kDa}$ ). STF was filled up to $100 \mathrm{~mL}$ into cell and maintained at $37 \pm 1^{\circ} \mathrm{C}$ with continuous stirring on thermostatically controlled magnetic stirrer (Thermo Fisher Scientific, Massachusetts USA). At predetermined time intervals, $1 \mathrm{~mL}$ samples were withdrawn and replenished with STF in order to maintain the sink condition. The samples were analyzed UV- spectrophotometric analysis (Jasco v-630 spectrophotometer) at $\lambda$ $\max 261 \mathrm{~nm}$ and percentage drug released plotted against time [13, 19].

\subsubsection{In-vitro antifungal studies}

Anti-mycological study was performed by ditch plate technique using sabouraud agar culture medium. Optimized formulation F8, pure drug FLZ (+ control), marketed formulation (mkd) and blank as negative control. Fungal strains were streaked over the culture medium and incubated for 72 hours at $25^{\circ} \mathrm{C}$ in incubator [20-23]. Followed by measuring the one of inhibition the results were plotted for both fungal strains viz; blank Aspergillus niger and Candida albicans.

Acknowledgements: This publication was supported by the Deanship of Scientific Research at Prince Sattam Bin Abdulaziz University, Al-Kharj, Saudi Arabia.

Author contributions: Concept - M.M., F.F.; Design - M.M., F.F.; Supervision - M.M.; Resources - M.M., F.F., M.A.K..; Materials - F.F.; Data Collection and/or Processing - M.M., F.F., M.A.K; Analysis and/or Interpretation - M.M., F.F.; Literature Search - FF.; Writing - M.M.; Critical Reviews - M.M., F.F., M.A.K.

Conflict of interest statement: The authors declared no conflict of interest.

\section{REFERENCES}

[1] Awwad S, Mohamed Ahmed AHA, Sharma G, et al. Principles of pharmacology in the eye. Br J Pharmacol. 2017; 174(23): 4205-4223. [CrossRef]

[2] Queckenberg C, Fuhr U. Influence of posture on pharmacokinetics. Eur J Clin Pharmacol. 2009; 65(2): 109-119. [CrossRef] 
[3] Ringvold A. Corneal epithelium and UV-protection of the eye. Acta Ophthalmol Scand. 1998; 76(2): 149-153. [CrossRef]

[4] Gaudana R, Ananthula HK, Parenky A, Mitra AK. Ocular drug delivery. AAPS J. 2010; 12(3): 348-360. [CrossRef]

[5] Agrahari V, Mandal A, Agrahari V, et al. A comprehensive insight on ocular pharmacokinetics. Drug Deliv Transl Res. 2016; 6(6): 735-754. [CrossRef]

[6] Thomas PA. Current perspectives on ophthalmic mycoses. Clin Microbiol Rev. 2003; 16(4): 730-797. [CrossRef]

[7] Teweldemedhin M, Saravanan M, Gebreyesus A, Gebreegziabiher D. Ocular bacterial infections at Quiha Ophthalmic Hospital, Northern Ethiopia: an evaluation according to the risk factors and the antimicrobial susceptibility of bacterial isolates. BMC Infect Dis. 2017; 17(1): 207. [CrossRef]

[8] Ansari Z, Miller D, Galor A. Current Thoughts in Fungal Keratitis: Diagnosis and Treatment. Curr Fungal Infect Rep. 2013; 7(3): 209-218. [CrossRef]

[9] Klotz SA, Penn CC, Negvesky GJ, Butrus SI. Fungal and parasitic infections of the eye. Clin Microbiol Rev. 2000; 13(4): 662-685. [CrossRef]

[10] Patra, J.K., Das, G., Fraceto, L.F. et al. Nano based drug delivery systems: recent developments and future prospects. J Nanobiotechnol.2018; 16: 71. [CrossRef]

[11] Gooch N, Molokhia SA, Condie R. Ocular drug delivery for glaucoma management. Pharmaceutics. 2012; 4(1): 197211. [CrossRef]

[12] Akbarzadeh A, Rezaei-Sadabady R, Davaran S, et al. Liposome: classification, preparation, and applications. Nanoscale Res Lett. 2013;8(1):102. [CrossRef]

[13] Okura NU, Yozgatlıb V, Okurc MU, Yoltaşd A, Siafakab PI. Improving therapeutic efficacy of voriconazole against fungal keratitis: Thermo-sensitive in situ gels as ophthalmic drug carriers. J Drug Deliv Sci Technol. 2019; 49: 323333. [CrossRef]

[14] Maggi L, Friuli V, Chiesa E, et al. Improvement of the Firocoxib Dissolution Performance Using Electrospun Fibers Obtained from Different Polymer/Surfactant Associations. Int J Mol Sci. 2019; 20(12): 3084. [CrossRef]

[15] Cidade MT, Ramos DJ, Santos J, Carrelo H, Calero N, Borges JP. Injectable Hydrogels Based on Pluronic/Water Systems Filled with Alginate Microparticles for Biomedical Applications. Materials (Basel).2019; 12(7): 1083. [CrossRef]

[16] Wickson B. Particulate Matter: USP Requirements and Particle Identification. 2019.

[17] Shastri D, Patel L, Parikh R. Studies on in situ Hydrogel: A Smart Way for Safe and Sustained Ocular Drug Delivery. J Young Pharm. 2010; 2(2): 116-120. [CrossRef]

[18] Modi G, Chandrul K, Padia M. Spectrophotometric estimation of Blonanserin in pure drug and pharmaceutical formulation. J. Chem. Pharm. Res. 2011; 3, (3): 670-675.

[19] Ahmed, M. M., Fatima, F., \& Mohammed, A. B. Olive Oil Based Organogels for Effective Topical Delivery of Fluconazole: In-vitro Antifungal Study. JPRI.2020: 32(25), 29-36. [CrossRef]

[20] Davis KE, Joseph SJ, Janssen PH. Effects of growth medium, inoculum size, and incubation time on culturability and isolation of soil bacteria. Appl Environ Microbiol. 2005; 71(2): 826-834. [CrossRef]

[21] Irimia T, Dinu-Pîrvu CE, Ghica MV. Chitosan-Based In Situ Gels for Ocular Delivery of Therapeutics: A State-of-theArt Review. Mar Drugs. 2018; 16(10): 373. [CrossRef]

[22] Giuliano E, Paolino D, Fresta M, Cosco D. Mucosal Applications of Poloxamer 407-Based Hydrogels: An Overview. Pharmaceutics. 2018; 10(3): 159. [CrossRef]

[23] Liu Y, Liu J, Zhang X, Zhang R, Huang Y, Wu C. In situ gelling gelrite/alginate formulations as vehicles for ophthalmic drug delivery. AAPS PharmSciTech. 2010; 11(2): 610-620. [CrossRef] 